Dwyer, Arienne M. 1998. The Texture of Tongues: Languages and Power in China. In Willam Safran, ed., Nationalism and Ethnoregional Identities in China. Frank Cass, pp. 68-85. Preprint.

\title{
The Texture of Tongues: Languages and Power in China
}

\author{
Arienne M. Dwyer
}

\section{Introduction}

The way speakers and nations use language reflects the power relationships of a society. Languages are inherently dynamic, interactive, and multi-layered. Nationstates are stabilizing and isolating to preserve territorial integrity. Multilingual nationstates seek to preserve territorial boundaries in part by delimiting hierarchical boundaries between their languages.

Mandarin, canonized as the standard language, stands at the pinnacle of a metalinguistic hierarchy which mirrors the vertical basis of power in China today. State language policies establish official minority languages (and Chinese "dialects") under the arching umbrella of the Chinese state; yet their domain, or horizontal scope, is strictly constrained through prescriptive standardization. The dynamic change and variation of spoken languages is reduced to a single text.

This paper explores the tension between this codifying imperative of the Chinese state and the dynamic force of speakers. I survey Chinese language policy in theory and practice, then focus on the expressions of power through language use.

\section{Language policy in China: theory and practice}

According to the Chinese Constitution, all 56 minzu ("nationalities") are equal and enjoy equal status "in the Zhonghua Minzu Chinese Nation".1 "Official policy condemns both 'Han Chauvinism', the belief that the Han, or Chinese, are superior to other groups, and 'Local Nationality Chauvinism', which denies that groups other than the Han are integral parts of the Chinese nation." 2 But in practice, only nonHan speakers are referred to as minzu. Even though the Hans are one of the 56 official minzu, there are no Chinese research departments and no Han students at the

\footnotetext{
1 Stevan Harrell, 'Linguistics and hegemony in China' International Journal of the Sociology of Language 103 (1993), p. 97.

2 Ibid.; cf. Linda Benson and Ingvar Svanberg, 'The Kazaks in Xinjiang' in Benson and Svanberg (eds), The Kazaks of China: Essays on an Ethnic Minority (Uppsala: Studia Multiethnica Upsaliensia 5, 1988), p. 56.
} 
central Min₹u daxue (Minzu university) in Beijing, and there are no articles on Han Chinese linguistics in the national journal Min₹u yuyan (Min₹u Languages).

With the stability of the P.R.C. ever paramount, the focus of Chinese language policy has shifted from the description and definition of languages (1949-1980's) to the limited accommodation of tightly-constrained diversity.

The goal of language policy of the 1950's was to establish parameters for the extent of cultural and linguistic variation within the Chinese nation-state. For the first time, language-survey teams were dispatched to minority regions to determine the linguistic and cultural affiliation(s) of the groups in question. This data, together with social and political considerations ${ }^{3}$, was used to establish or reject min₹u status for lesser-known groups. The languages of major groups (with large populations and long-standing written traditions) were accorded recognition early on. Language policies of the 1950's mandated the use of "one or several of the commonly-used local languages and scripts". 4 This permitted Uygur, Tibetan, Mongolian, and Yi to achieve stature as a regional standard languages (though subordinate to Mandarin Chinese), and provided for the limited maintenance of all other subordinate languages. ${ }^{5}$ However, behind the language-maintenance rhetoric was an assimilationist policy in the name of the greater Chinese nation. As CASS scholar Dob (Daobu) describes, “in the late 1950's, the relevant government department...had overstated the commonalities of the different nationalities, played down their differences, and propagated the idea that the assimilation of all nationalities and languages would soon be accomplished". 6 For the central government, the preservation of ethnic languages was perceived to conflict with the preservation of the nation itself.

\footnotetext{
${ }^{3}$ Sun Hongkai, one of China's most prominent linguists, acknowledges that "the desires of the nationality concerned" can be as important as linguistic criteria for determining min₹u status. He cites Buyi and Zhuang, Sibe and Manchu as closely-related pairs that because of their separate minzu status are nonetheless considered separate languages (at least within China) (Sun Hongkai, 'Language recognition and nationality' International Journal of the Sociology of Language 97 (1992), pp.16-17).

${ }^{4}$ CASS (Chinese Academy of Social Sciences) Nationalities Research Institute and Chinese Nationalities Commission (eds), 'Minzu wenzi gongzuo sishi nian jishi' Zhongguo shaoshu minqu (Beijing: Zhongguo Zangxue Press , 1992), p. 223, emphasis added.

${ }^{5}$ Media, schools and educational materials are provided in demographically dominant minority languages, but Chinese-language broadcast air time, newspapers, and educational opportunities outstrip those in subordinate languages by a factor of at least 3:1. In theory, however, every language is deserving of such institutional support: "Each and every minority Nationality has the freedom to develop its own language and script, preserve or improve its traditions, customs, and religious beliefs." (Item 43 of the Common Programme, first meeting of the People's Political Consultative Conference, September 29, 1949, ibid., p. 219). [Translations are my own unless otherwise indicated.]

${ }^{6}$ Dob (Daobu) White, 'The position and role of minority languages and their writing systems in China' International Journal of the Sociology of Language 97 (1992), p. 53.
} 
After thirty years, beginning in 1979-1980 a more accommodationist policy was implemented. For those groups with orthographies and national status, minoritylanguage schools and presses were reopened; for many of the smaller groups, orthographies were devised. For all groups, distinct minority "customs" (such as religions, legends, and rites of passage) were again acknowledged to exist. Twenty years ago a Salar folklorist was jailed for publishing the legend of the Salars' Central Asian origins, yet today their origins outside of China are now officially-sanctioned history. ${ }^{7}$

By the mid-1980's, the minority nationalities were identified and "known": the language(s), history, and customs of each group had been described and codified in national publications. The borders of China where so many minorities live were similarly well-defined and well-protected. Minority language policy thus moderated and became more flexible with regard to local conditions. A limited linguistic diversity is now encouraged as long as this variation falls within the parameters defined by the Chinese state. Thus several mutually unintelligible varieties of Chinese, Tibetan, and Yi are recognized, but they are identified as dialects, not languages. "Bilingual" educational is available for certain minority languages from preschool through the university level, but a mastery of Chinese is a necessary condition for study at the tertiary level. As ethnolinguistic groups, the minority nationalities are officially on a par with the dominant Hans, but even recent scholarship continues to primitivize and exoticize the former. One article on the Zhuang, one of China's largest minority groups, notes that the "Zhuang's song festival ... provides linguistic evidence of sex worship, totemism, and the custom of inhabiting caves". ${ }^{8}$ This highly limited accommodation of diversity serves to reinforce the definitions of ethnicity established during the 1950's.

This goal of minority-language containment is furthered by population and orthography policies. The population transfer and migration of Han Chinese from eastern China to the peripheral regions has firmly established the national standard, Mandarin Chinese, as the primary language of government, scholarship, and to some extent, commerce. In Xinjiang, for example, the Han population has increased almost twenty-fold since $1953 .{ }^{9}$

\footnotetext{
${ }^{7}$ Han Zhanxiang 1992, personal communication.

8 Zhou Qingsheng, 'Aspects of Chinese ethnosociolinguistic studies: a report on the literature' International Journal of the Sociology of Language 97 (1992), p. 67.

${ }^{9}$ The Han population of Xinjiang was 300,000 according to the 1953 census, 5,695,409 in 1990, and continues to increase steadily (Benson and Svanberg, p. 35; Xinjiang Weiwuer zizhiqu renkou jicha bangongshi (eds), Xinjiang Weiwuer ziz̧hiqu 1990 nian renkou jicha qiliao (Ürümchi: China Statistical Publishing House, 1992), p. 297).
} 
In a society which is united by a common writing system, orthographic policy is one of the cornerstones of language policy. One of the main rationales for referring to the Chinese "dialects" as part of a monolithic "Chinese language" is the existence of a common Chinese writing system. Minority-language writing systems are also used to unite speakers of divergent languages (e.g. the so-called 'Standard Yi script' of Yunnan).

Orthography policy is usually designed to contain "major" languages and ensure the obsolescence of "minor" languages. Languages which already had scripts at the time of the formation of the People's Republic were automatically accorded a measure of prestige for having 'civilization' (wenhua). These existing writing systems were tolerated, and in the 1950's 14 new or revised Latin-based scripts were introduced for 10 minority nationalities. ${ }^{10}$ However, the purpose of such policies was to effect a transition from the minority language to Mandarin Chinese. Many of the languages with long written traditions such as Tibetan, Mongolian, Yi, and Uygur were encouraged to switch to Latin-based scripts modeled after pinyin (the P.R.C. transliteration system for Chinese), with the goal that it would facilitate their learning of Chinese. More subtly, each group that adopts a pinyin-based script also adopts the Chinese state's way of framing language, and is thus a step closer to having been brought into the Chinese fold. This policy, while successful amongst many groups previously without orthographies, failed dismally with those minorities with previous written traditions. The Uygurs and Qazaqs, for example, resumed use of an Arabicbased script within a few years.

\section{An Unwritten Text: The structure of Languages and Power in China}

The implementation of these policies have in effect created a five-tiered language hierarchy in China:

(1) The NATIOnAL STANDARD, Mandarin Chinese.

(2) REgional StANDARD LANGUAGES, including regional varieties of Mandarin Chinese, and regional minority standards, such as Yi, Mongolian, Tibetan, and Uygur.

(3) Primary minority LANGuages, i.e. those with historical and/or modern prestige, usually large populations, and moderate political clout. These include Qazaq, Korean, Manchu, Zhuang, Naxi, and the non-standard Chinese dialects.

(4) SECONDARY MINORITY (or SUB-MINORITY) LANGUAGES, which include the remaining low-prestige, usually unwritten languages with small numbers of

10 White, p. 52. 
speakers and no clout, e.g. Evenki, Salar, Va. Often these groups have larger numbers of speakers elsewhere, hence their designation as Dispersed Nationalities by the 1950's government.

(5) UnRECOGNIZED LANGUAGES, usually unclassified mixed languages such as Wutun (Gansu) and Aynu (Xinjiang), or languages lumped in with others, such as Wakhi ("Tajik", Xinjiang).

In the above hierarchy, PRIMARY and SECONDARY are political (not linguistic) terms. A given group's status in this hierarchy bears on the implementation of central government policy directives. PRIMARY MINORITIES may be accorded limited preferential treatment, with partial native-language schooling, print and even broadcast media provided, such as the Sibes. SECONDARY MINORITIES usually have no infrastructural support (e.g. schools) since they rarely have official orthographies. However, certain areas have affirmative action-type programs in place. At the Ili Teacher's College in western Xinjiang, college-bound Özbek and Salar students are eligible for the few freshman-class slots the school reserves for them. ${ }^{11}$

\section{Negotiating Power through Language Policy}

\subsection{Packaging the Chinese Nationalities from the Civilizing Center}

Language policy in China is reminiscent of much of Chomskyan linguistics: first the bounds of an idealized language are defined, then real-language data is found to fit the model. In China's case, the model is a vertically-integrated, limited-multilingual state. It is very much like binding a barrel with steel bands to strengthen its capacity to hold water. At the center of the barrel are the Han Chinese lands and civilization; at its edges are the minorities.

In a society which reveres the written canon, the existence of an orthography and body of written materials is taken as indicative of some degree of cultural sophistication. Conversely, national minorities without orthographies were and are still considered backwards. One frequently hears members of orthographied minority groups (as well as Hans) refer to minorities without orthographies as 'without civilization'.

Spoken language is fluid, and exhibits a great deal of variation among different speakers, locales, and time periods. In contrast, written language is fixed and codified. In sponsoring the creation of standard orthographies and grammars for

11 Shahandek 1992, personal communication. 
languages, the Chinese state has been establishing central control over the speakers of these languages by the codifying and packaging of these languages.

This codification is achieved by constructing a "literary" standard for grammars of unwritten minority languages. The Salar language spoken in Amdo Tibet, for example, is Turkic in origin but a mixed (Turkic, Chinese, and Tibetan) language today. Its vocabulary is at least $20 \%$ Chinese and $10 \%$ Tibetan. ${ }^{12}$ Morphological and syntactic structures have been borrowed wholesale from these latter languages. Yet linguistic works published in China to date treat Salar as a Turkic language with a few loan words; the Salar-speaking area considered "most standard" by Chinese scholars is also the one that most preserves Turkic features. When a Salar orthography was proposed in the early 1980's, it was based on the language of that 'most-Turkic' area. This view has since gained currency among the locals, who will urge visiting linguists to visit that area to hear 'real Salar'. Furthermore, Salar grammars and lexicons emphasize the Turkic elements in Salar, but omit most Tibetan and Chinese features. Works on Salar morphosyntax contain descriptions of verb tenses that modern Salar no longer has, or perhaps never had. Salar's simplified grammatical paradigm, typical of mixed languages, is not tolerated.

The mutability of languages runs counter to the codifying aims of the metalinguistic hierarchy of the Chinese state. Languages, like ethnic identities, are constantly in motion, localized, interactive, and subjective, not static and codified.

\subsection{THE LITERARY CANON}

Scientific research in China on languages and their speakers has operated under the assumption that ethnolinguistic identity is fixed, global, discrete, and objectifiable. In the view of Chinese academia, each of the 55 officially-recognized minority nationalities constitutes (and has always constituted) a bundle of immutable features: an ethnonym, a history, a language, a locale, and "ethnic" customs. (The Hans are assumed to be the default or unmarked group.) Since the research teams first went out to minority areas in the 1950's, following central directives several important series on minority languages, histories, and literature have appeared. Most series have one volume per national minority. In essence, these works serve to justify and promote the officially-defined feature bundle for each minority group. In so doing, the central government is creating an imagined community (in the Andersonian sense) in negotiation with its minorities. These reference books put weight behind such definitions of language and ethnicity in China.

\footnotetext{
12 Based on the quantitative analysis of Salar texts I collected in situ, 1991-1993.
} 
Of particular note is the Series of Five Minority Problems (Minqu wenti wu々hong congshu, or simply Wutao congshu). The individual series are as follows:

(1) The Minority Nationalities of China (Zhongguo shaoshu minzu) (single volume)

(2) Concise Histories of the Chinese Minority Nationalities (Zhongguo shaoshu minzu jianshi)

(3)Concise Grammars of the Chinese Minority Nationalities (Zhongguo shaoshu minzu yuyan jianzhi)

(4) Introductions to the Autonomous areas of Chinese Minority Nationalities (Zhongguo shaoshu minzu zizhi difang gaikuang)

(5) Surveys of the Social History of Chinese Minority Nationalities (Zhongguo shaoshu minzu shebui lishi diaocha)

The editors of the above book The Minority Nationalities of China ${ }^{13}$ note that while that particular volume was published by People's Press in Beijing, that all the series volumes are "published by other presses of the central authorities as well as by presses in every region."

Actually, only the autonomous areal introductions and the occasional surveys are published locally, and the latter are especially sporadic. The Concise Histories and the Concise Grammars are uniformly published in Beijing by Nationalities (Minzu) Press. Moreover, most of the authors are senior researchers at the Nationalities Research Institute at the Chinese Academy of Social Sciences (CASS). These linguists conducted research in the minority communities as outsiders (almost all are Han and male); from that they wrote these reference works. This constitutes a clear statement of centralized power.

Grammars of minority languages were commissioned as an outgrowth of minority classification efforts in the late 1950's. Now there exists one Concise Grammar for each officially-identified minority language.

As of 1992, Shanghai Wenyi Press had published 40 collections of minority folktales covering 46 officially-recognized minorities. Volumes including the folktales of the remaining nine groups are planned. Yet all of these collections are Chinese translations. As such they have limited value as folklore and no value as language samples.

13 Zhongguo shaoshu minzu editorial group (eds), Zhongguo shaoshu min₹u (Beijing: Renmin, 1981), p.396. 


\subsection{BEIJING AS THE SEAT OF KNOWLEDGE}

Authorities on Chinese minorities are overwhelmingly Hans in Beijing. If we look at the Concise Grammars just of the Turkic languages in China, we find that all eight principal authors are Han, and all are based at the prestigious Nationalities Research Institute at the Chinese Academy of Social Science in Beijing. Seven of the eight are male. ${ }^{14}$

As a foreign field linguist working in China, I am certainly in no position to criticize outsiders going into communities to record linguistic and cultural information. But by having almost exclusively the members of the dominant Han group author the standard (and in many cases, the only) work on the subject suggests that authority rests in the hands of the Han. That they all hail from Beijing reinforces the notion that the minority languages are under strict central control. Since cultural knowledge is bundled in language, this display of State control extends into the very heart of minority identities.

Ethnic affiliation by no means determines the appropriate qualifications and skills of good fieldworkers/researchers. But if the principal investigator is an outsider, it is crucial that $\mathrm{s} /$ he collaborate intellectually with the local scholars to a significant degree. In this regard, the Concise Histories fare much better than the Concise Grammars: those about groups living in Xinjiang are almost all published in Xinjiang, and at least co-authored by a scholar who is a member of that group.

\subsection{BEIJING CONTROLS ALL, EVEN TIME ITSELF}

Officially, all of China's vastness is one time zone. Be they in Kashgar, Lhasa or Kunming, China's infrastructure operates on Beijing time. Close to the winter solstice, a bank employee in Kashgar (3000 kilometers from Beijing) gets to work in pitch black at 8:00 A.M. Beijing time, even though the sun doesn't rise until about 11 A.M. In Xinjiang and Tibet however, an informal local time system two hours earlier than Beijing time has long been in use. While Hans generally go by Beijing time, minorities tend to use the local time. In making dates and appointments, each person's choice of a time system constitutes a public display of their acceptance or rejection of the hegemonic efforts of Chinese authority.

\footnotetext{
${ }^{14}$ Data from the Concise Grammars of Uygur, Qazaq, Qïrghï, Tatar, Özbek, Tuva, Salar, Sarïgh Yogur; the ethnic and professional affiliations of the authors from Junast (Zhaonasitu) and Li Hengpu (eds.), Dangdai Zhongguo minzu yuyanxuejia. (Xining: Qinghai renmin, 1989). The principal author of the work on Özbek was based in Ürümchi at the time of publication, but since 1992 has been at CASS in Beijing. Two grammars had native-speaker co-authors (Özbek and Tatar).
} 
This cavalier show of control over time itself characterizes the hubris of the Chinese state. It manifests itself not only in efforts to demonstrate control over synchronic time, but in quite successful attempts to manipulate historical time. Modern geopolitical boundaries and recently-created "Minority Nationalities" are projected backwards in time to serve the present Chinese state. ${ }^{15}$ Thus, western Yunnan, Inner Mongolia, and Xinjiang have "always been inseparable parts of China", just as the Uygurs have "always" been a part of an Uygur nationality. Modern minority languages and literatures in particular have been pressed into service to reinforce the official parameters of min₹u. Speakers of modern Uygur dialects are considered to be direct descendants of eleventh century sedentary oasis-dwelling Turkic-speakers of "Xinjiang", even though there is ample historical evidence that these medieval Eastern Turkistani oasis dwellers spoke Indo-European and Mongolian as well as a variety of Turkic languages/dialects. ${ }^{16}$

\subsection{Ethnonyms, Language names, and the Politics of Linguistic CLASSIFICATION}

Another aspect of the officially defined feature bundle that the government has skillfully manipulated is in nomenclature: the names of languages and their speakers.

$$
\text { THE “TAJIKS” (TAJIKE) }
$$

There is a group of 26,000 Indo-Iranian speakers in the Pamirs near the Karakorum Highway, where Xinjiang meets Pakistan, Afghanistan, and Tajikistan. They are predominantly Wakhi (Vakh), but also Sariqoli (Sarykoli). The Chinese government, however, calls them all 'Tajiks'. Linguistically, socially, and economically, though, these are two separate groups. From a linguistic point of view, Wakhi and Sariqoli are closely related: both are Eastern Iranian languages. Still, there are significant differences in their sound systems and grammars. But Tajik (Tadzhik) belongs to the West Iranian languages and is quite different from both Wakhi and Sariqoli. ${ }^{17}$ As the language of education and administration in neighboring Tajikistan, Tajik has become the 'flagship language' for Pamir-Iranian speakers. In Tajikistan, dominant Tajik is used as a common language between speakers of different Pamir languages. However, Tajik is not spoken in China.

\footnotetext{
${ }^{15}$ This concept of projecting the twentieth-century concept of 'Nationality' backwards in time comes from discussions with Jonathan Lipman in 1994.

${ }^{16}$ Re: Indo-European, see Rene Grousset, The Empire of the Steppes [tr. Naomi Walford] (N.J.: Rutgers, 1970), p. 96; re: Mongolic and Turkic, see Mirsultan Osmanov, Hazirqi zaman Uygur tilining di'alektliri (Ürümchi: Xinjiang Education Press, 1990), pp. 98-115.

17 Bernard Comrie, The Languages of the Soviet Union (New York: Cambridge University Press, 1981), p. 161.
} 
In the Concise Grammar of Tajik (sic), the author neatly sidesteps this problem with brain-bending logic. The bulk of the book is devoted to a grammar of "Tajik", but the final chapter on "Tajik dialects" (added twenty years after the original draft grammar) informs us that "Wakhi (Wahan) and Sariqoli (Salikuer) are the main dialects of Tajik in China". Furthermore, "Wakhi colloquial speech is used among Tajik Wakhis in China". ${ }^{18}$

Why the insistence, then, on "Tajik"? It is certainly more expedient than recognizing two separate groups. But why not call the Iranian-speaking peoples in China "Wakhis"? "Tajik", apparently, is more ethnically and geographically neutral — since neither the Wakhi nor the Sariqoli are Tajik — and Tajik is a standard language with an orthography.

This lumping together of ethnolinguistically distinct groups under a neutral ethnonym is common on the Chinese periphery, from the "Gaoshan" on Taiwan (which include at least seven mutually unintelligible ethnolinguistic groups) to the "Uygur" of the Tarim Basin (which include Turkic-Iranian and Turkic-Mongolic mixed languages). The Austronesian groups remaining on Taiwan identify themselves along ethnolinguistic lines (Paiwan, Atayal, Ami); the sedentary Turkicspeakers of Xinjiang identify themselves by region: Turpanliq (Turfani), Qäshqärlik (Kashgari). The labels 'Gaoshan' (Ch. high-mountain) and 'Uygur' (a medieval Eastern-Turkic ethnonym revived only in the 20th century) encourage member of these groups to see themselves as more or less homogeneous. Interestingly, at least in the case of 'Uygur' and 'Gaoshan', the etymology of the imposed ethnonym fills a different conceptual niche than the native ethnonym: the imposed Gaoshan is a geographical label; their self-appellations are ethnolinguistic. In contrast, the Uygurs identify themselves primarily on a geographic basis, whereas the imposed ethnonym is quasi-ethnolinguistic.

$$
\text { “KIRGIZ” (KEERKEZI) }
$$

The modern Qirghï (Kyrgyz) are referred to as Keerkezi, but the eponymous people of Kyrgyzstan (Qirghizstan) and their medieval-to-premodern ancestors the two groups share are referred to as Jierjisi. ${ }^{19}$ Although Jierjisi has some historical precedent, ${ }^{20}$ its use with modern Qirghïz of Kyrgyzstan suggests that the Central

\footnotetext{
18 Gao Erxie, Tajikeyu jianz̧̧i (Beijing: Minzu, 1985), p. 101.

${ }^{19}$ E.g. Chen Yanqi and Sa Sha (eds), Xiyu yanju shumu (Ürümchi: Xinjiang renmin, 1990), p. 307.

${ }^{20}$ Xiajiasi was used during the Tang dynasty to refer to the former Qïrghïz, following a Tang dynasty transcription form. See for example Chen and Sa, p. 92.
} 
Nationalities Commission hopes to de-link or at least subtly weaken the connection the Xinjiang Qïrghï have with their fellow Qïrghïz across the border. ${ }^{21}$

$$
\begin{aligned}
& \text { “EASTERn Yugur” (DONGBu Yuguzu, SHERA Yogur) } \\
& \text { "Western Yugur” Xibu Yuguzu (SARÏG YOGUR) }
\end{aligned}
$$

The people now known as the Yugurs of Gansu include two different groups, one Mongolic (Shera Yogur) and one Turkic (Sarïg Yogur). Both "native" ethnonyms mean 'Yellow Yog(h)ur". 'Eastern Yugur' and 'Western Yugur' are designations by the Chinese state. These groups fit none of the Stalinist criteria for status as one nationality: they share neither language, economy, "culture" (beyond both being Buddhist), nor ancestry. They just happen to be located in the same part of Gansu, and have come to share certain linguistic features as part of the Chinese-TurkicMongolic-Tibetan melting pot there. "Only in the past forty years have [both the Mongol and Turkic Yugurs] started to identify themselves as Yugu as opposites to other groups in the region." These people "cannot be defined as Tibetans because of language, and not as Mongols because the other groups of Mongol peoples are latecomers in the area". 22

Sitting in our armchairs in Beijing, we read in The Minority Nationalities of China that "the Yugur nationality has two languages from different language families".23 Turning the book (or its logic) upside down, we might instead conclude that two different ethno-linguistic complexes have been grouped together into one nationality.

\subsection{METING OUT OFFICIAL ORTHOGRAPHIES}

In theory, since 1949 minority groups have enjoyed government support for either:

(1) maintaining an existing orthographic system (or reviving a historical one), or

(2) establishing a pinyin-based Latin orthography for those languages without one.

In practice, speakers of marginalized "minor" languages may have difficulties obtaining official approval of any written standard. For example, some Salars in

\footnotetext{
21 Personal names within and without China's borders are also subject to disassociation through transliteration: "Ismail", for example, is rendered as Simayi for Ismails within China, but as Yisimaier for those outside China.

${ }^{22}$ Sabira Ståhlberg, 'A Central Asian-Chinese Ethnic Melting Pot: The Case of the Gansu Corridor' (ms., 1995), p. 13; cf. Ståhlberg, Der Gansu-Korridor: Barbarenland diesseits und jenseits der Großen Chinesischen Mauer (Hamburg: Verlag Dr. Kovac, 1996).

23 Zhongguo shaoshu minzu, p. 586.
} 
Qinghai proposed a Latin-based orthography in 198324. This was rejected twice by the government (Han Jianye 1992, pers. comm.). Complicating matters was that Salar elders did not want a Latin-based orthography; because of historical precedent and their religious beliefs, they preferred one based in the Arabic script.

This conflict between lead to a stalemate: their requests for an Arabic-based script were turned down several times. This likely was related to the government's fears of the development of pan-Turkic sentiment in western China as much as it had to do with the purportedly exorbitant cost of printing books in a Salar script. In the end, there is no script, Arabic- or Latin-based, and it is a dead issue.

At the other extreme, establishing multiple orthographies for one min₹u leads to fragmentation: the Yi, for example, now have 3 standards: Northern, Guizhou, and Yunnan. ${ }^{25}$

\subsection{MARGINALIZING UNRECOGNIZED GROUPS}

To their credit, in the last decade researchers in China have begun to recognize a few mixed languages and study contact-induced language change. However, such research occurs within the same minority-language parameters outlined above. Those languages and their speakers who do not easily fit existing categories tend to be overlooked or marginalized. Q-S. Zhou mentions that during the 1980's two “creoles or mixed languages" were "discovered" in Northwestern China: Äynu (Tarim basin, Xinjiang) and Wutun (southern Gansu). ${ }^{26}$ It is laudable that such information is being published in an international forum. But he continues: "A few hundred years ago the ancestors of the Äynu moved into Xinjiang from Iran and lived in compact villages scattered in the Uygur community" (ibid.). Unfortunately, a few hundred years ago, the sedentary Turkic-speaking Tarim basin denizens did not refer to themselves as Uygur, did not see themselves as a community beyond their own oases, and did not call their land Xinjiang. Furthermore, historical records are too unclear to state definitively that the Äynus originated in "Iran". Although the Äynus are an Iranic-speaking people, it is well-known that Indo-Iranic speakers predated Turkic speakers in the Tarim basin. So it could well have been the "Uygurs" (i.e.,

${ }^{24}$ Xunhua Sala zizhixian, Qinghai minzu xueyuan minzu yanjiusuo yuwen yanjiushi, eds. 1983. Sala wenzi fang'an (draft). ms. Created in consultation with the Xinjiang Language and Script Work Committee, the proposed standard was identical to Latin-script Uygur and Qazaq (with the inexplicable addition of an ' $\mathrm{N}$ ' with a tail $(\mathrm{N}, \mathrm{n}$,) for the velar nasal [ng]).

25 David Bradley, 'Language Policy for the Yi' (Paper presented at the Yi Studies Conference, University of Washington, 1995), p.8.

26 Zhou Qingsheng, p.63. 
Turkic peoples) that moved into "Xinjiang". At the very least, modern ethnolinguistic paradigms are best confined to the present.

In addition to projecting modern paradigms backwards onto the murky past, one other method of marginalizing problem languages and their speakers is to overlook their mixed status entirely. This is the favored technique with mixed languages that are already officially recognized and thus canonized as pure, monolithic entities. Baonan, Salar, and even surprisingly Northwestern Chinese come to mind. All three groups have been in sustained and heavy contact with speakers of Mongolic, Turkic, Tibetan, and Chinese languages. Although Baonan is Mongolic and Salar is Turkic in origin, high percentages of their vocabulary (30-40\%) consists of Chinese and Tibetan words. Both have borrowed the Chinese copula shi and a host of other syntactic paradigms. Northwestern Chinese, a variety of Mandarin, has lost one of its tones and reversed its word order under Turkic and Mongolic influence. ${ }^{27}$ Baonan, Salar, and Northwestern Chinese fit the criteria for mixed or creolized languages, but are not recognized as such. To do so would contradict the notion that minorities and minority languages are discrete entities.

\section{8 “BILINGUAL” EDUCATION}

Another arm of minority-language policy has been so-called bilingual education. "Bilingual education" has a much more specific meaning than merely "education in two languages' as the term seems to imply. As in the U.S., "bilingual education" really refers transitional schooling in the native language(s) while students master to the dominant language.

From 1950 to 1978, Chinese schools offered sink-or-swim immersion in Standard Chinese from day one for minorities in elementary schools. This is still euphemistically referred to as 'direct transition' 28 or as 'the expedient model'. ${ }^{29}$ A Salar academic researcher, now 37 with a college degree, had this to say from his experience of this pedagogical technique: "I did not speak a word in the classroom for the first four years. Then I finally started speaking Chinese, but my sentences came

\footnotetext{
27 Mantarô Hashimoto advanced quite convincing evidence that Northwestern Chinese is a creole language (Hashimoto Mantaro, 'The Altaicization of Northern Chinese' in J. McCoy and Timothy Light (eds.), Festschrift for Professor Nicholas Bodman (1984)). Language-contact data on Baonan (Bao'an) is from Charles N. Li, 'Languages in contact in Western China' Papers in East Asian Languages v1 (1983), pp. 21-51; that on Salar is from my own fieldwork.

28 White, p. 55.

29 Zhou Yaowen, 'Bilingualism and bilingual education in China' International Journal of the Sociology of Language 97 (1992), pp. 37-45.
} 
out all backwards. It wasn't until middle school that I was able to function in Chinese". 30

Since 1978, bilingual education for minorities has been policy but more incrementally implemented in different areas. There are many methods, ${ }^{31}$ but the overall goal remains the same: to introduce Chinese at some point, and gradually achieve the transition from the speakers' native language to Chinese.

\subsection{DRY GRAMMAR BOOKS IN SERVICE OF THE CHINESE STATE!}

Mandarin Chinese is considered the default language, or the sun around which minority-language planets orbit. Even grammar books are pressed into service for linguistically (and culturally) sinicizing minority education. So linguists are kept busy turning out endless contrastive grammars of Minority Language $x$ vs. Standard Chinese. The stated aim is to help minority students learn Chinese more quickly. So, for example, the grammar will mention the difficulty Turkic speakers have with the Chinese retroflexes $s, t s t s^{h}$. Unfortunately they rarely provide concrete examples of language errors to enliven their wooden prose. So here's one: Chinese Shanghai $\left[\mathrm{say}_{51} \mathrm{xai}_{312}\right]$, Qazaq $\left[\mathrm{t}^{\mathrm{h}} \mathrm{ayq}^{\mathrm{h}} \mathrm{ai}\right] .^{32}$

The writing of comparative grammars (of languages within a family) is strongly discouraged, particularly in a transnational language family. The rationale, of course, is that comparative grammars stimulate horizontal links between ethnic identities and thus seriously challenge the Chinese state. Comparisons between languages, if unavoidable, must be done between languages spoken in China. Data may not be drawn from speakers of these languages in other countries. So the Concise Grammar of Miao makes no mention of the relationship of "Miao" in China to the Hmong in Southeast Asia; similarly, from the Comparative Dictionary of the Chinese Turkic Languages (Minzu, 1990), one would gather that languages such as Özbek (Uzbek), Qazaq, and Qïrghï are spoken nowhere else but in China.

One striking illustration of the bounds of comparativist permissibility is the recent (1992) Central Minorities College textbook, An Introduction to the Turkic Languages (Tujueyu gailun). The editor Li Zengxiang presents most of the information himself, including a lengthy introduction to the history of the Turkic peoples and their languages, the phonology of modern Turkic languages, and a survey of research on these languages. The entire chapter on the classification of the Turkic languages,

\footnotetext{
30 Musa Abdu 1992, personal communication.

31 Zhou Yaowen, pp. 40-41, Zhou Qingsheng, pp. 60-61, White, pp. 55-56.

32 I am indebted to Ahmetjan Qaybaruli for sharing moments of his childhood hilarity with me.
} 
however, is translated entirely from the works of well-known non-Chinese (mostly Russian) Turcologists on the subject.

The mid-book switch of authors is striking, and reflects the more subtle constraints on acceptable topics in linguistics. Classification is off-limits because it is a political minefield: proposing a new linguistic grouping could easily upset a delicate ethnic balance somewhere in China. If Uygur and Özbek were shown to be more closely related than Shanghai and Cantonese Chinese, the Uygurs might start to get fancy ideas of Pan-Turkism. Conversely, if two Tibetan dialects were proposed to be separate languages but all speakers self-identified as Tibetan, these speakers might accuse the State linguists of divide-and-conquer tactics.

Part of the function of linguists and linguistic scholarship in China is to stabilize the perception of languages and linguistic/cultural groups. In this capacity, transnational linguistic or cultural comparison is strictly frowned upon.

In the Turkology textbook, one could argue that Li, in presenting foreign scholarship on linguistic classification, was simply deferring to the highest authorities on the subject. If this were true it would be highly uncharacteristic of Chinese scholarship: ever since the invention of gunpowder (or at least since the founding of the P.R.C.), relevant theories are incorporated into Chinese scholarship and reborn as "Chinese theories", usually without a whisper of attribution. ${ }^{33}$ But in the Turkology book, the foreign author's names constitute section titles and are very prominent.

One final word on the framing of the Turkic peoples: when referring to "Turkic" (Tujue) in association with "ethnic group" (minzu), the grapheme "language" (yu) is always inserted between the two: "Turkic-speaking peoples" (Tujueyu minzu) instead of "Turkic peoples" (Tujue minzu). "Turkic peoples" clearly identifies the ethnicity of these people as "Turks", implying that the seven Turkic groups now within China's borders are really one people. Far safer is the label "Turkic-speaking people", which is linguistically specific but ethnically generic, and thus allows for the application of a Chinese state-approved label: Uygur, Qazaq, Yugur, Salar, Tuva, etc.

33 To give but one example: in one 1992 article published in an international journal (Zhou Qingsheng, p. 62), a Chinese author defines and distinguishes types of code-switching, attributing the theory to a short 1988 article by an author in Guizhou, yet never mentioning the enormous body of work on the topic which preceded him, such as Gumperz 1982 and Ferguson 1972. 


\section{The Chinese Languages}

\subsection{THE UNIFYING MYTH OF “THE HAN LANGUAGE” (HANYU)}

Today in the P.R.C., the generic term for spoken and written Chinese is Hanyu, the "language of the Hans." It refers increasingly (especially in academic writing) to the Standard language, but can also refer to all Chinese languages ("dialects"). Interestingly, this term has been gaining ground over the formerly widespread Putonghua "the common language." The utilitarian, socialist-flavored label Putonghua connotes an ideal common language spoken across China by ordinary folks. The more recent preference for Hanyu reflects a shift towards language identification along clearly ethnic lines. Before, the distinction was [ \pm proletarian]; now the important distinction is $[ \pm \mathrm{Han}]$. Even after achieving the socialist revolution, the Chinese state has found its peripheral peoples still restless.

The term Hanyu is used with particular frequency to describe earlier stages of Chinese, e.g. Gudai Hanyu ("Old Chinese"). These include all the modern Chinese dialects. These historical dialects are referred to as one ancient Han entity going back 5000 years to the dawn of Han Chinese civilization. This again reflects the homogenizing and backwards-projecting agenda of the modern Chinese state in its constant drive to legitimize its power. Except for its use as a label of two historical dynasties and their people, the term "Han" was not associated with a pan-Chinese language until quite recently. The distinction and standardization of an official, hegemonic language (initially Guoyu "National Language," later Putonghua) did not occur until early in this century. ${ }^{34}$

\subsection{ACCORDING MINORITY-LANGUAGE-LIKE STATUS TO CHINESE “DIALECTS”}

Chinese as spoken across China was hardly uniform or unified. But by grouping these languages as though there were one, the state demoted the status of these languages to mere "non-standard dialects", thus strengthening the authority of the Mandarin-speaking center.

Except for Mandarin, speakers of the six other modern Chinese "dialects groups", the Min, Yue, Wu, Gan, Xiang, and Hakka (Kejia), are found in central and southern China. Despite being called "Chinese dialects" nationally and internationally, they are largely mutually unintelligible. The dialect names correspond to historical regions

34 Jerry Norman, Chinese (New York: Cambridge University Press, 1988), p. 133. 
(which were often statelets) of eastern and southern China. ${ }^{35}$ These groups lived among and likely even included speakers of Austroasiatic languages, as well as Chinese speakers. In earliest times, linguistic and archaeological evidence suggests that the region was highly multilingual and multicultural. Toponyms in southeastern China today provide strong evidence that Austroasiatic people lived in that area very early on. There is even linguistic evidence that convincingly suggests that the historical Yue (now "Cantonese" speakers) actually spoke Austroasiatic languages. ${ }^{36}$

Policy mandates that schooling be conducted nationally in Putonghua so that speakers of non-standard Chinese dialects can be brought up to speed on the national standard language, Mandarin. All schooling in Chinese is expected to be conducted in Putonghua. From the point of view of language attitudes, however, there are two types of non-standard Chinese: higher-prestige and low-prestige "dialects". In this way it is much like the minority-language dominance scale: there is the dominant Standard Language (Mandarin), and then all the other dialects in a subordinate ("primary minority") position. Non-standard Chinese "dialects" are lower prestige than Mandarin and do not enjoy nearly the infrastructural support in education, administration, and the media. In many ways, speakers of non-standard Chinese dialects are worse off than their minority counterparts: "major minorities" (e.g. the Uygurs) have access to limited schooling, radio and television, and even governmental affairs in their own language. Not so for their Min and Yue Chinese comrades. Yet while external pressure to use Mandarin is strong, speakers of these "dialects" often strongly identify themselves with their language and locale. There is a definite insider's pride in being a Shanghainese, or a Min speaker in Fujian.

\subsection{QINGPUHUA: STANDARDS WITHIN STANDARDS}

An audio tape of Qinghai Chinese xiangsheng (stand-up comedy, sometimes called "Cross-talk" 37 ) is a delightful example of how conscious people are about language standards. On this tape, produced in Xining, one of the duo acts the part of a native speaker of Qinghai Chinese, while the other pretends he is a visitor from the nation's capital. The visitor is a know-it-all who looks down on the locals yet claims he has no trouble understanding their every word. His opposite decides to test his listening comprehension. He utters a great stream of words with sibilants. In Standard Chinese, this speech would contain clear distinctions between retroflex and palatal sounds. But since these are not distinguished in Qinghai Chinese, the stream of

\footnotetext{
${ }^{35}$ Except for 'Hakka' 'guest', a label by Yue speakers given to the non-Yue "barbarians" who had moved in among them.

36 Norman, p. 18.

37 Su Falin and Peng Honghe, Qinghai fangyan xiangsheng. (Xining: Kunlun Recordings, 1989). [audio cassette].
} 
speech just sound like the buzzing of an angry bumblebee. Of course, the arrogant visitor fails miserably.

The humorous tension between supercilious standard-language speakers and babbling locals reveals the gulf of prestige between the two varieties of Chinese. Such language attitudes have fostered the development of an intermediary variety of Chinese in Qinghai. It is a compromise, non-standard standard Chinese which partially incorporates the sound system and vocabulary of the Qinghai vernacular (tubua) into Standard Chinese. It is an local adaptation of Standard Mandarin Chinese that enjoys quasi-official sanction in the local broadcast media and state enterprises (including educational institutions), which refer to it as "Qing(hai) Pu(tong)hua", "Qinghai's Common Language". In other Mandarin-speaking areas, other regional standard varieties have developed which emulate Standard Mandarin. But Qingpuhua not only emulates Standard Mandarin, it also represents it. Qingpuhua is not merely a linguistic bridge between the dominant standard and local varieties. The fact that locals have given it a name suggests that it has become a metalanguage: it is at once a functioning lingua franca, and a statement about language itself. The existence of Qingpuhua constitutes a statement about the local identity and the limits of central government control.

\section{China from Within and Without: The Effects of Adhering to a Single Text}

The Chinese state cannot encourage real autonomy and multiple ethnolinguistic identities outside of the overarching zhonghua minzu - for Hans or "minorities" because these horizontal entities threaten the vertical basis of power. Plural identities and autonomy are strongly decentralizing forces. In the last fifteen years, the entrepreneurial boom ("socialism with Chinese characteristics", a.k.a. euphemistic capitalism) and massive demographic shifts of an increasingly mobile population has been challenging the homogenizing efforts of the Chinese nation-state. I met Uygurs and Hans from Xinjiang who had moved to Shenzhen, and Huis and Salars who had taken teaching jobs in Hainan. Such increased demographic mobility, however, has not thusfar resulted in a greater acceptance of multiple identities in society. Both the dominant group and minorities themselves reinforce negative stereotypes of minorities and non-prestige Hans. Thus a Chinese-educated Qazaq intellectual from Gansu told me, "Whenever I go to Beijing I feel like such a hick". As the east-coast cities are flooded with skilled and unskilled fortune-seekers, intra-Han conflicts are emerging as well. Han speakers moving to Beijing from Xinjiang are teased for their drawl ("hao de heeeen! [Great!]") and "toneless Chinese", even though both groups speak "the same dialect" natively.

This illustrates the interaction of language, speaker perceptions, and the Chinese state. I have shown the codifying and textualizing pressure exerted by the 
Chinese state on its minority languages. I have proposed a re-examination of assumptions about the purportedly static texture of language in a multilingual society, and a re-examination of the paradigm of central control.

This is not merely a campaign for the maintenance and encouragement of linguistic and ethnic diversity in China. The purpose here has also been to demonstrate the misinformation generated when the minority-language paradigm of the Chinese state is propagated unwittingly by researchers overseas.

Many people, even specialists, unquestioningly accepting the backwards projection of history and the use of Chinese ethnonymic labels. For example, in a recent Chinggis Khan exhibit ${ }^{38}$, the forebearers of the Mongols were described as "the Eastern Hu" even though $b u$ never was an ethnic group, but just meant any "barbarians to the north and west of China proper." Another example is the widely-read Englishlanguage reference work, The Languages of China. It states that: "The Uigurs and their close relatives, the Yellow Uigurs [=Sarig Yogur=Western Yugur] and the Salar are found almost exclusively within Chinese borders. They are both in name and in fact indigenous peoples of China". ${ }^{39}$

The degree of certainty with which his assertions are made is misleading. Much is still unknown about the history of these peoples and their languages. But it is clear that when the Turkic-speaking ancestors of the modern Uygurs settled in the area, it was not "China" as we know it today. ${ }^{40}$ The Uygurs (and Sarïg Yogurs) may be indigenous to the region, but they are not indigenous "to China".

Languages are highly textured things, compact masses of cultural knowledge. Languages and their speakers in China have been codified and hierarchically ordered in the constant drive for legitimization of the Chinese state.

\footnotetext{
${ }^{38}$ Chinggis Khan exhibit, Royal British Columbia Museum, Victoria, B.C. and L.A. County Museum of Art, 1995.

39 S. Robert Ramsey, The Languages of China (Princeton: Princeton University Press, 1987), p. 185, emphasis added.

${ }^{40}$ The Salars are most likely indigenous to Transoxiana south of Samarkand, not China. There is linguistic and historical evidence that the Sarigh Yogurs are not Uygurs at all, but may be Siberian Turks historically (Geng Shimin and Larry Clark, 'Sarig Yugur Materials' Acta Orientalia Academiae Scientaiarum Hung. 46 n2-3 (1992), p. 193). The Uygurs and Sarïgh Yogurs can only be considered indigenous to China if the modern political boundaries of the People's Republic are imagined backwards in time. While the Hans have a long history of contacts with the Uygurs (and Sarigh Yogur) and had settlements in Turkistan, Chinese control of the Tarim and Junggarian basins waxed and waned over time with the rise and fall of oasis-states and Chinese dynasties. China laid claim to the Eastern Turkistan frontier region in 1784, but the region was not firmly in Chinese control until the establishment of the P.R.C.
} 